entropy by a system representing a positive loss of virtue. Clarity is necessary in distinguishing between the 'first-law' efficiency of a system and the thermodynamic efficiency. Dr. N. Kurti (Clarendon Labor. atory, Oxford) deplored the conventional distinction between heat and thermodynamics, and suggested that a single course, implanting faith in thermodynamics by the statistical approach, should serve for all university students whatever their specialist interests. Dr. R. S. Silver (John Brown Land Boilers, Ltd., Clydebank) presented the practical engineer's point of view. Thermodynamics, he said, is badly taught because its concepts are of a subtlety beyond the grasp of the average physicist and the average teacher. Hence, the exposition of the second law is not normally adequate to equip the engineer to face industrial problems. He advocated teaching in terms of ordered and disordered energy rather than work and heat-ordering rather than energy conversionand abandoning the usual idea of efficiency for a proportioning ratio between ordered and disordered energy expressed in terms of temperatures.

Dr. A. W. Barton (City of London School) opened the second day's proceedings, speaking on "Physics in the School Curriculum". The historical development of the subject is a treatment which marches in line with the development of the individual boy, with the early passion for collecting facts and slowly emerging capacity to relate them to general principles. Physics is, he said, an educational discipline equalled only by Greek. Dr. Barton's lively exposition of his own teaching methods was a memorable feat, which illustrated his general argument convincingly.

Mr. W. Llowarch (Institute of Education, London) spoke on "Non-Specialist Science in the Sixth Form", outlining the scheme he developed during his time at Stowe School. For a year's course, the boys were divided into three groups, each doing one term of biology, physics and chemistry in rotation, the work being taught by specialists. Lectures on isolated subjects of special or topical interest had proved on the whole preferable to a more continuous course, and biology seemed the most generally appreciated of the three. After discussing the aims of the course, Mr. Llowarch gave some examples of topies which had been particularly successful.

"Education through Physics" was the title of the talk by Prof. F. A. Vick (University College of North Staffordshire). One of the aims of education, he said, is to toughen the mind by exercise on problems. The historical approach, while not generally useful, can be valuable in showing the devious routes by which accepted theories arose. Students should be encouraged from the beginning to consult original papers, and in the final year at the university, while continuing a broad education, should reach the frontiers of knowledge in one or two places. In subsidiary physies courses, the future technologist should regard the subject not as a mere tool, but as a contribution to his full education. Prof. Vick regards physics, freed from the mechanistic outlook of the nineteenth century, as a living subject which stands equal to classical and modern studies as the core of a complete education.

Mr. N. R. Hanson (University of Cambridge) then described the undergraduate course in the history and philosophy of science, developed during the past five years in the University of Cambridge. The aim, he said, is not to bumanize the scientist by superposing a little culture, but to help him to understand what he is doing. History leads to a better appreciation of an idea by tracing the steps in its development. Philosophy, as concerned with the meaning of concepts, and why they are fashioned in one way rather than another, may help a man to be a better physicist. Mr. Hanson explained the close collaboration by which the course is dovetailed with the tripos lectures in physics, and spoke of the enthusiasm with which it has been received, and the growth of the Philosophy of Science Club at Cambridge.

G. R. NOAKES

\section{PROPOSED MUSEUM OF SCIENCE AND TECHNOLOGY IN THE NORTH-WEST OF ENGLAND}

A MEETING was held on February 18 at the A College of Technology, Manchester, to consider a proposal to establish a museum of science and technology in the north-west of England. Interest in such a museum came from a number of quartersfrom industry and from academic and educational life. Sympathy and support for this scheme has also been shown by municipal and other bodies. The meeting was attended by representatives of industry, the universities, trade and professional bodies and representatives of museums in Manchester, York, Birmingham and Liverpool.

A resolution was moved by Mr. L. Lever, M.P., and Dr. P. F. R. Venables, and carried unanimously, that a museum of science and technology be established, and an executive committee be appointed in order to investigate the details involved in setting such a project in action, and to report back at a subsequent meeting of the body as ihen constituted. The executive committee consists of Mr. H. G. Greg (for the Textile Institute), Mr. Niel Pearson, Prof. L. Rosenfeld (Department of Theoretical Physics, University of Manchester), Mr. R. M. Sayce (keeper, Manchester Museum) and Dr. P. F. R. Venables (principal, Royal Technical College, Salford); Mr. P. Lennox-Kerr (editor, Skinner's Silk and Rayon Record) and Dr. W. Mays (Department of Philosophy, University of Manchester) are the joint secretaries.

The project for a museum of science and technology arose from the joining together of two streams of interest. In industry, especially the textile and engineering industries, there has for a long time been felt the need for establishing an industrial museum to take account, among other things, of the economic history of the region. At the University of Manchester there was a group of people interested in the establishment of a museum for the history of science and technology. It was felt by them that the history of science should take a more important place in university education, where there is an everincreasing need for relating the diverse fields of study which make up the university curricula. In the promotion of the study of the history of science, a museum plays an essential part, comparable to that of a laboratory in the experimental sciences.

The intention is to establish a science museum which will show the development of industry in the northwest of England from the early days of the Industrial Revolution to the present day in relation to the scientific background. It is hoped that it will embrace a number of fields of inquiry-from the natural sciences to economic history-and lead to 
their integration, and in this way provide a link between industry and the academic world.

Such a museum can act as a repository of documents and objects of great historical value, which otherwise run the risk of disappearing through decay or neglect. It is hoped that when established it will be a centre of research where the impact of the sciences upon each other and upon technology can be studied. Its activities would cover pure science, discovery and invention, and manufacture and use. Future developments and sociological implications would be taken into account. There are already clear indications that the proposed scheme is of public, as well as specialist, interest. As well as covering the history of science it will endeavour to acquaint the general public with the most recent scientific advances and their industrial applications.

At a time when technical knowledge is becoming increasingly important, such a museum can play a vital part in modern education. Early introduction to large areas of scientific knowledge and its application is desirable if we are to prepare young people to enter such fields of study. Bringing young people into such an institution would give them a chance of tracing the evolution of specific representative manufacturing processes from hand processes to modern automatic equipment, and stimulate in them the desire to play a part in the continuation of such developments. It has been suggested that a preliminary exhibition be held to indicate the scope of the museum, and to interest the public in its activities.

\section{CARNEGIE TRUST FOR THE UNIVERSITIES OF SCOTLAND REPORT FOR 1953-54}

T

HE fifty-third annual report of the Carnegie Trust for the Universities of Scotland, covering the year ended September 30, 1954*, records increasing preoccupation of the Executive Committee with appeals for assistance from students who have been deprived of their bursaries by the local education authorities through failure to pass the requisite degree examinations at the appropriate times. In all but the most exceptional cases, the Trust's assistance is limited, however, to the class fee, and no maintenance grant can be made. In the year under review, the number of students assisted increased from 1,301 to 1,408 , almost entirely in science and medicine, the amount expended increasing from $£ 20,003$ to $£ 22,007$. While the Executive Committee recognizes that, with the length and expense of the courses in dentistry and medicine, many students, despite substantial bursary awards from education authorities, are severely taxed to make ends meet, it points out that, particularly where an education authority bursary is held, there can be no assumption that additional assistance from the Trust is automatically forthcoming. Every application is considered on its own merits, and clear evidence of need must be shown.

Expenditure on the research scheme increased by about $£ 2,000$ to just short of $£ 35,000$, and the Executive Committee regards the scheme as continuing to yield satisfactory results. While no upper limit has been fixed for the sum expended on

* Carnegie Trust for the Universities of Scotland. Fifty-third Annual Report (for the Year 1953-54). Pp. iv +72. (Edinburgh : T. and A. Constable, Ltd., 1955.) fellowships, scholarships and grants, in practice the amounts required have not varied significantly from year to year. Certain other limits are at present fixed by annual decision: these include $£ 4,000$ to the universities for distribution at their discretion to lecturers and professors engaged in research projects at home and abroad; $£ 500$ to the Royal Society of Edinburgh; and $£ 6,000$ to the scheme by which not more than ten senior members of the staffs in the universities are afforded an opportunity of three months or more to pursue their research investigations abroad. Uncertainties as to expenditure lie rather in the growing region of guarantees against loss on publication of books of a kind that might have great difficulty in getting acceptance by a publisher.

Besides details of grants made under the ninth quinquennial distribution (October 1, 1952-September 30,1957$)$, the abstract of accounts, lists of publications by fellows, scholars and recipients of grants received since September 1953, of papers assisted by grant for the session, and of fellowships, scholarships and grants under the research scheme, there is appended the usual report upon the work of investigators under the research scheme during the year. In the mathematical, physical and engineering section, high praise is given to D. M. Colvin's highpressure ionization chamber investigations and to W. D. Munn's work on problems relating to abstract algebra; K. M. Swanson has made steady progress in his study of nuclear magnetic resonance effects in semi-conductors, and Dr. E. Wolf, as a result of his study of interference and diffraction of light, has proceeded to a research fellowship at the University of Manchester. In medicine, I. A. Macpherson's work on the development of tissue-culture methods in the study of poliomyelitis and Jean D. Garven's work on the estimation of 5-hydroxytryptamine in extracts of animal tissues are specially mentioned.

In the chemistry section, Dr. T. R. R. MeDonald's $\mathrm{X}$-ray crystallographic investigation of ammonium bifluoride, which confirmed views assuming a resonance state for the bifluoride ion and afforded no evidence of interaction between the fluorine and the hydrogen atoms of the ammonium ion, is specially commended. Mr. R. Logan's investigation of phosphate metabolism in the rabbit, using radioactive phosphorus as indicator, showed that under in vitro conditions the cell nuclei of rabbit liver take up phosphate from the cytoplasm. Similar results were obtained with the spleen and the intestinal mucosa; but no evidence of the reverse passage was obtained in the liver or the spleen, although a small but significant transfer occurred in the intestinal mucosa. Reference is also made to the work of A. N. Hamer, D. Calvert and R. C. Taylor at the University of St. Andrews on the construction and use of apparatus for applying mass-spectrography to the measurement of ionizing potentials and identifying products of pyrolysis of organic compounds. L. R. Newlands has obtained a series of triazole compounds by the aetion of aromatic aldehydes on a new derivative of mandelic acid obtained from mandelic amidate hydrochloride and phenylhydrazine. C. A. J. Goodlad's work on the enzymes of rat liver which hydrolyse phosphoric esters of sugars has demonstrated the complex nature of these phosphatases. In the biological section special mention is made of G. D. Scott's work on the ecology and physiology of lichens, which has demonstrated the possibility of growing the fungal constituent of a lichen in pure culture, and of that of J. Weir on the ecology of the 